\title{
The shielding performance study of the sandwich board with different materials
}

\author{
Chengying $\mathrm{SHI}^{1, a}$, Zongshu $\mathrm{MEI}^{1, \mathrm{~b}}$ and Xinghui $\mathrm{CAI}^{1, \mathrm{c}}$ \\ ${ }^{1}$ The second artillery engineering university, xi 'an 710025,China \\ aemail: 920043582@qq.com, bemail: shicy@163.com, cemail: caixinghui@163.com
}

Keywords: Laminated plates, Shielding performance, MCNP, Flux

\begin{abstract}
This paper mainly studies the shielding performance, under gamma and neutron radiation, of three different laminated plate made of different materials. Through MCNP simulation test, making a comparison of particle flux size under the same gamma and neutron radiation. Coming to a conclusion that among three kinds of materials with same thickness, shielding performance of $\mathrm{Fe} / \mathrm{W} / \mathrm{Fe}$ is the best; At the same time, through the experiment, comparing the shielding performance of different thickness of Core board which are made of $\mathrm{Fe} /$ boron polyethylene/Fe, coming to a conclusion that in the laminated plate structure, the contribution rate of boron polyethylene plate in shielding is not high.
\end{abstract}

\section{Introduction}

As the existing threat of nuclear weapons on the battlefield, and in recent yeas, represented by Japan's fukushima nuclear accident, civilian nuclear accidents are becoming more and more frequency, the research of radiation protection material is becoming the key topics in the field of radiation protection. Composite shielding material is a type of the radiation protection materials developing rapidly in recent years. Compared with traditional metal shielding material, composite shielding material has the characteristics of qualitative light, cheap, and could change its composition according to the different radiation environment in order to achieve the optimization of shielding effectiveness. In the structure of shielding material, a variety of laminated plate is formed through welding, rolling pressure, having good comprehensive characteristics, such as both good shielding performance and the characteristics of high structural strength. In this paper, the shielding performance of laminated plate structure is studied, by MCNP experiments, comparing the shielding performance of gamma and neutron radiation of three different kinds of laminated slabs with different sandwich plate materials, $\mathrm{Fe} /$ boron polyethylene $/ \mathrm{Fe}, \mathrm{Fe} \mathrm{Fe} / \mathrm{Pb} / \mathrm{Fe}, \mathrm{Fe} / \mathrm{W} / \mathrm{Fe}$, with the comparison of shielding performance between lightweight composite materials and the traditional metal material.

\section{Model Construction}

By setting the neutron source and gamma ray source respectively, carrying on the simulation experiment for several different groups of shielding materials separately, the calculation model is set up as shown in figure 1.

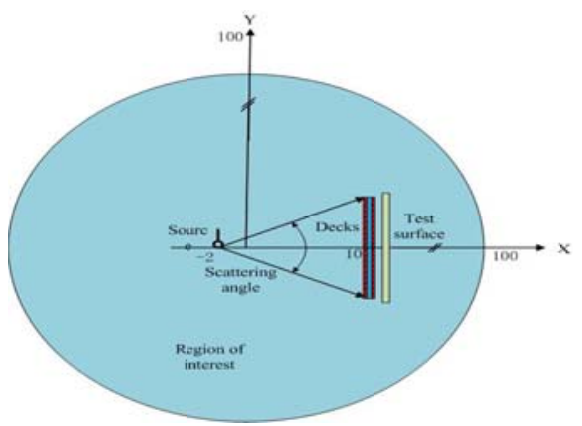

Fig. 1 Model diagram 
As shown in figure 1 , on the $X$ axis, in $X=2$ place setting a point source, $X=10$ for the decks' innermost, record surface is a rectangular plane parallelling to the decks, with the width of 10x10, and thickness of 1, using FMESH card, record each small grid body by detecting the surface flux, figure 2 is obtained by visualization software for calculation model writing in the procedure.

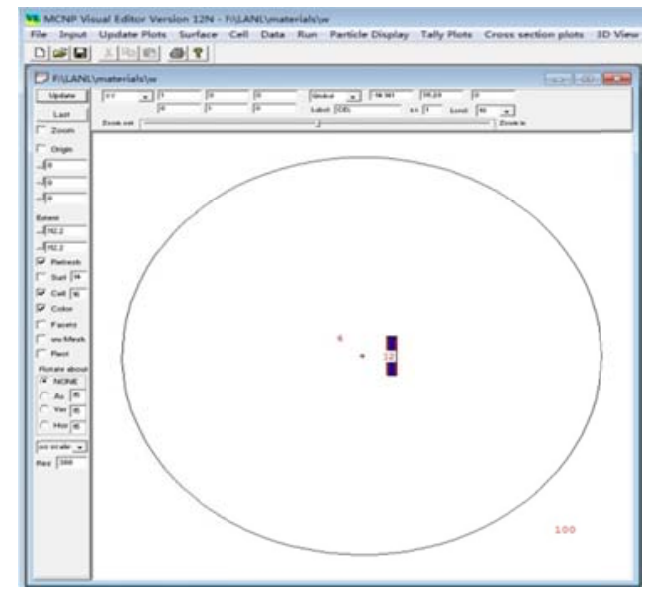

Fig. 2 Visual calculation model

Three Different Groups. This paper chooses three different group of materials, of which studying the gamma and neutron radiation shielding performance under condition of the same overall thickness and equal thickness of each layer. The three kinds of group are:

1) Group $1-\mathrm{Fe} / \mathrm{W} / \mathrm{Fe}$

2) Group $2-\mathrm{Fe} / \mathrm{Pb} / \mathrm{Fe}$

3) Group 3 - Fe/boron polyethylene/Fe

Tungsten is a kind of high $\mathrm{Z}$ values of radiation shielding material, with good shielding effect especially for space high-energy protons and electrons. Tungsten is a widely used radiation shielding material. This section is based on the MCNP simulation experiment of three group, $\mathrm{Fe} / \mathrm{W} / \mathrm{Fe}, \mathrm{Fe} / \mathrm{Pb} / \mathrm{Fe}$ and $\mathrm{Fe} /$ boron polyethylene/Fe, Getting the size of valume flux and energy distribution of three kinds of laminated plate of which the thickness is $1 \mathrm{~cm}+2 \mathrm{~cm}+1 \mathrm{~cm}$.

Neutron Source. For the further research on detecting the quantity and energy of neutrons. Conducting different Settings of the number of energy interval and space grid with FMESH4 counting card, the main purpose is as the following two points:

1) Setting 1 to the energy interval number, 10 to the length interval number of the square detect surface in the $\mathrm{Y}, \mathrm{Z}$ direction, getting the particle size of transmission neutron with indiscriminate energy in the detect surface.

2) Energy will be divided into 16 energy interval ranging from $0 \sim 2 \mathrm{MeV}, 10$ energy interval ranging from $2 \sim 4.5 \mathrm{MeV}$, the length of the square detect surface in the $\mathrm{Y}, \mathrm{Z}$ direction interval number is set to 1 , to get the particles flux of each energy range without space coordinates.

Through calculation, with the resulting data dealt with Tecplot and Matlab, getting transmission flux neutron spatial distribution and neutron energy diagram of each groups as shown in figure 3 .

Figure 3 illustrates the landing position of neutron through three kinds of shielding materials in counting surface is concentrated and consistent, and also three groups of experiments have lower relative error. Based on the neutron energy - flux chart, shielding performance of the three groups of high and low order is: $1>2>3$. 


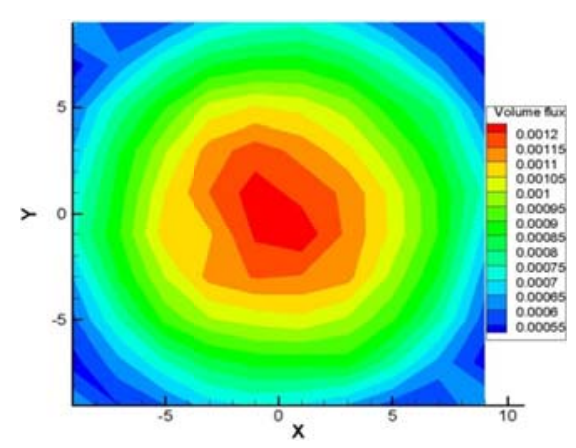

(1) Planar distribution of neutron valume flux of group1

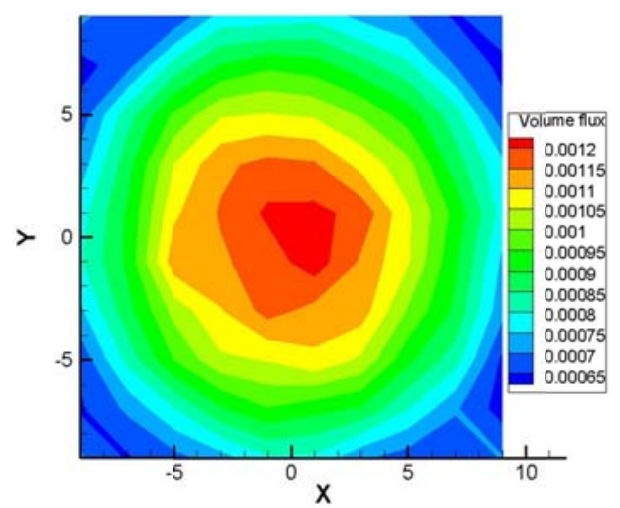

(3) Planar distribution of neutron valume flux of group2

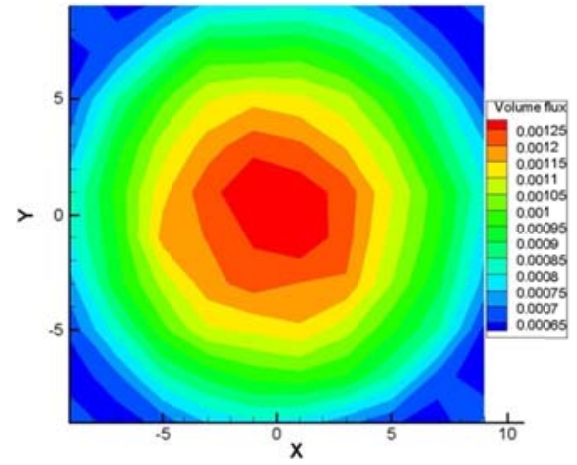

(5) Planar distribution of neutron valume flux of group 3

Fig. 3 Neutron valume flux and neutron energy spectrum

$\gamma$ Source. The source of MCNP input file INP is defined as photon source, getting photon valume flux and the relations of energy- flux of each groups as shown in figure 4:

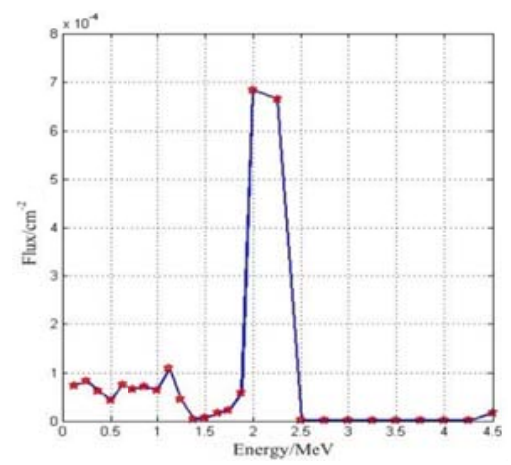

(2) Neutron energy-flux of group 1

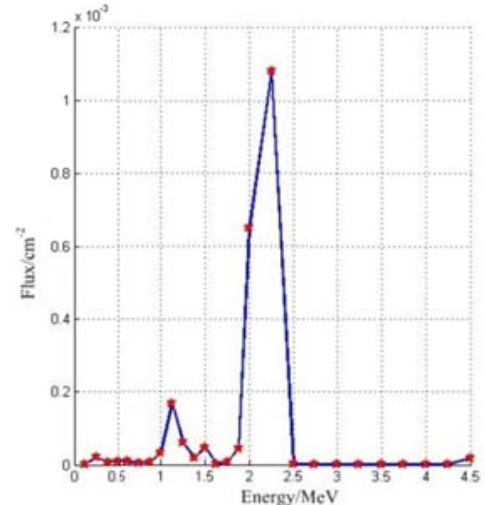

(4) Neutron energy-flux of group 2

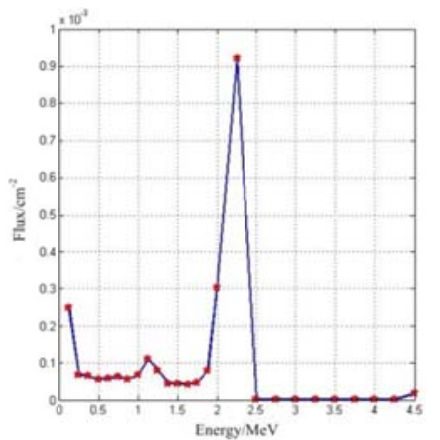

(6) Neutron energy-flux of group 3 


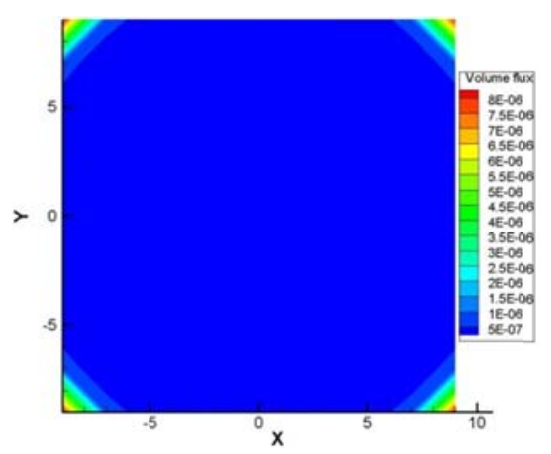

(1)Planar distribution of photon valume flux of group 1

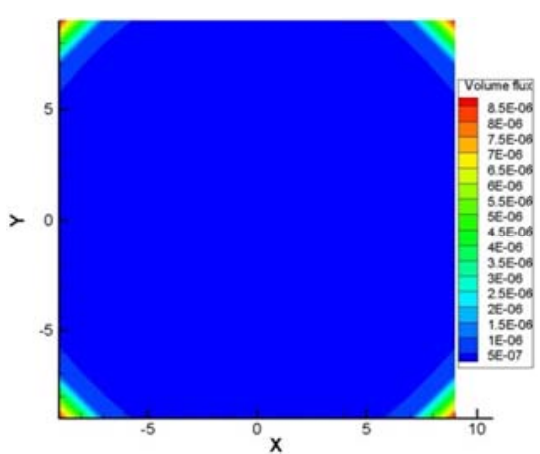

(3)Planar distribution of photon valume flux of group 2

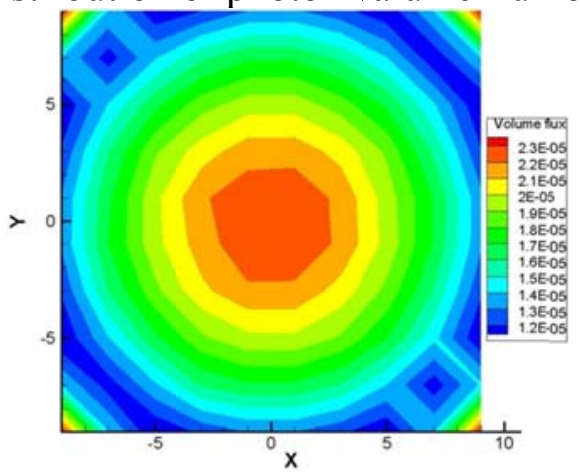

(5)Planar distribution of photon valume flux of group 3

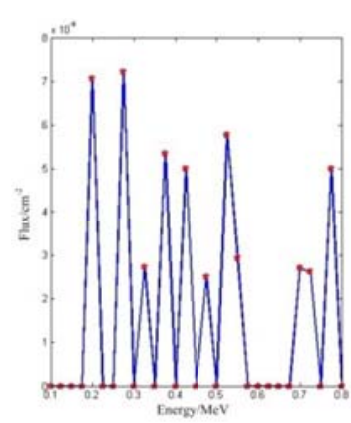

(2) Photon energy-flux of group 1

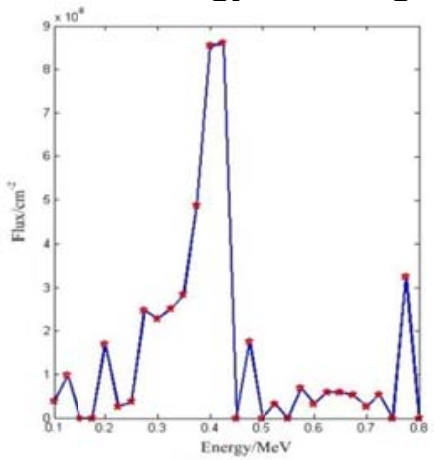

(4) Photon energy-flux of group 2

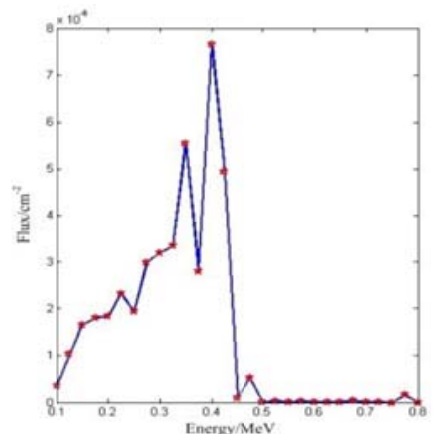

(6) Photon energy-flux of group 3

Fig. 4 Photon valume flux and neutron energy spectrum

By figure 4, the photon flux located in the center of detection surface is the largest. this part the detection photon is mainly transmitted photon, photon flux of other area is small, mainly for the diffraction photon and a small amount of bremsstrahlung photons. Through data analysis, shielding performance of the three kinds of material for high and low order is :1>2>3, as for the energy flux diagram, group 1 small one order of magnitude than group 2, small three orders of magnitude than group 3.

\section{Shielding Performance with Different Thickness of Core Board}

In order to study the influence on the shielding performance of shielding plate Fe/boron polyethylene/Fe when the core board is designed to be different thickness. this section intends to conduct simulation experiment of MCNP for four different core board thickness of shielding plate, which are $20 \mathrm{~cm}, 15 \mathrm{~cm}, 10 \mathrm{~cm}, 6 \mathrm{~cm}$ 。Still using FMESH4 card as counting card, record its flux, the results as shown in Figure 5. 


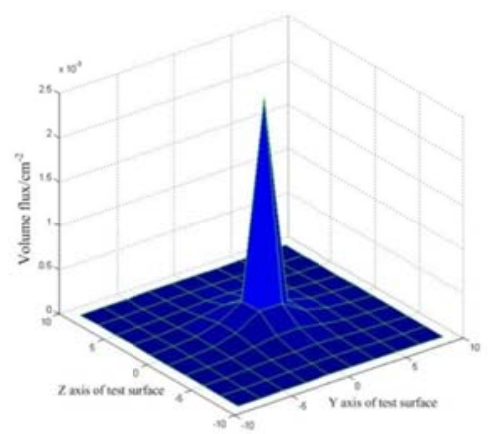

(1) thickness $6 \mathrm{~mm}$

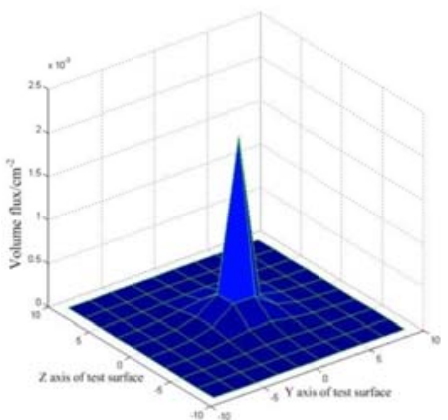

(3) thickness $15 \mathrm{~mm}$

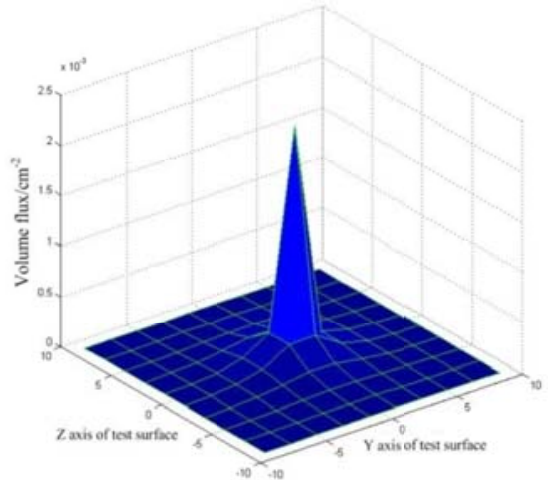

(2) thickness $10 \mathrm{~mm}$

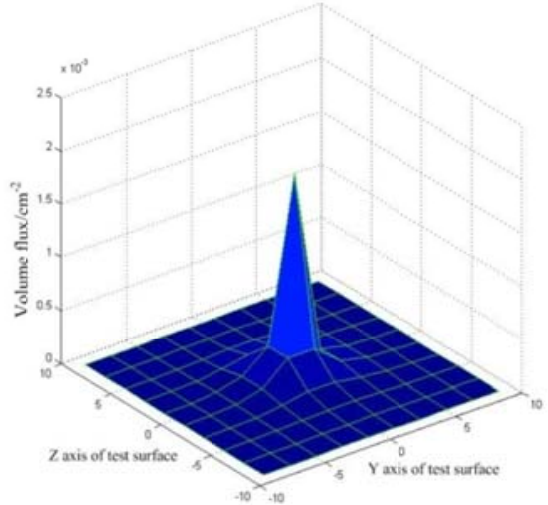

(4) thickness $20 \mathrm{~mm}$

Fig. 5 Flux of different core board thickness

Figure 5 illustrates that while the thickness of core board from big to small, transmission particle flux is similar to law of diminishing body, In order to observe more intuitively, to sandwich plate thickness and the relationship between the radiation photon flux, detect 100 rules arranged on the surface of the mesh in the $\mathrm{Z}$ axis to ten, calculating the average of each photon flux equal interval, and the data visualization processing get sandwich layer thickness of four different flux tank shell material body size of histogram。

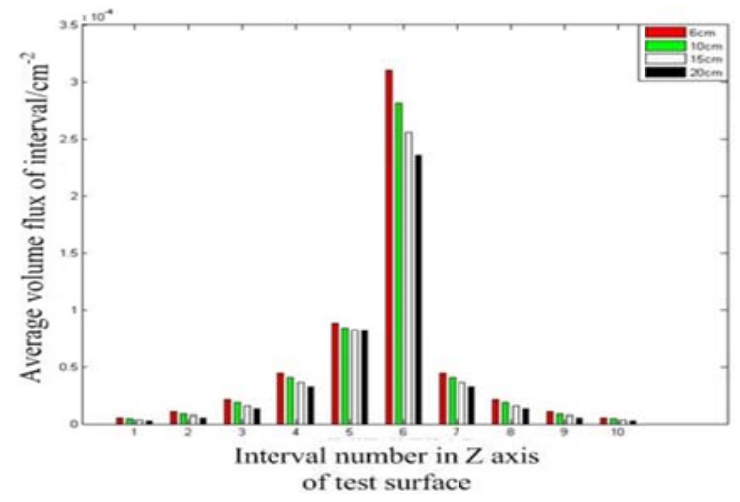

Fig. 6 Photon flux histogram of different thickness of core board

As shown in the figure 6, the boron polyethylene in the gamma radiation resistance of hull material contribution is not large, as the thickness of core board of boron polyethylene material from $2 \mathrm{~cm}$ to $0.6 \mathrm{~cm}$, The degradation of the gamma radiation resistance performance is not big, so the core board made of boron polyethylene in shielding performance is not outstanding. but considering the characteristics of its light weight, low price and underground structure in the space is large, gamma, neutron radiation strength is limited, still can use the material as shielding materials in a variety of occasions. 


\section{Conclusion}

The composite shielding material, boron polyethylene, has a good shielding performance on gamma and neutron shielding, and in the same level of $\mathrm{Pb}$. Although compared with metal tungsten the shielding performance is lower, but due to the high cost of tungsten makes its application limited; As a laminated plate shielding material core board, boron polyethylene, on the thickness of gradient, the shielding performance change is not obvious, should try to reduce the thickness while using. Enhancing its shielding performance can be realized by changing the composition ratios.

\section{References}

[1] Hu Huasi. Optimal design of new radiation shielding material[J]. Atomic energy science and technology, 2005,

[2] Liu Zixia, Lu Haichun, Chenming, etc. Different materials on the gamma attenuation coefficient of MCNP simulation[J]. Nuclear electronics and detection technology, 2013.

[3] Jia Jianyuan. Mobile application dynamic response nuclear explosion shock stability analysis[J]. Journal of applied mechanics, 1995.

[4] Briesmeister.J.F. MCNP: A General Monte Carlo N - Particle Transport Code, Version 4 A: LANL Report LA - 12625 - M [R]. New Mexico: Los Alamos National, 1993.

[5] Hao Fanhua, Hu Guangchun, Liu Suping. Plutonium of monte carlo method for the sample source gamma energy spectrum[J], Journal of physics, 2005, 54(8): 2523-2529.

[6] Zhang Lianping, Wei Mengfu, Li Ju. Specific shape source of gamma radiation field simulation study[J]. Nuclear technology, 2005, 28 (11): 821-826.

[7] Raymond.J.J. The Nuclear arsenals of maintenance-based on science [J]. Journal of Nuclear weapon, 2004, 3(4): 1-5.

[8] E.Zarkadoula, S.L.Daraszewicz, Duffy.D.M, etc. The Electronic effects in high-energy radiation damage in iron [J]. Journal of Physics: Condensed Matter, 2014, 26 (2):829-842. 